\title{
Doppler-echocardiographic findings in a patient with persisting right ventricular sinusoids
}

\author{
R. JenNi, M. RitTer, L. von SEgESSER AND F. Real \\ Medical Policlinic and Clinic for Cardiovascular Surgery, University Hospital and Department of \\ Cardiology, Children's University Hospital, Zürich, Switzerland
}

KEY WORDS: Right ventricular myocardial sinusoids, Doppler echocardiography.

The Doppler-echocardiographic features of persisting right ventricular myocardial sinusoids are presented. An 18-year-old patient with persisting right ventricular sinusoids had undergone comissurotomy for critical pulmonary artery stenosis at the age of 12 months. Follow-up catheterization at the age of 17 years revealed no signs of residual pulmonary artery stenosis, outflow tract obstruction or pulmonary hypertension. No shunt could be documented. High systolic velocity jets within the myocardial sinusoids were recorded by means of continuous-wave Doppler. Pulmonary artery blood flow velocity was recorded mainly consequent to atrial contraction and was reduced during right ventricular ejection period, thus reflecting impaired systolic and diastolic right ventricular function.

\section{Introduction}

The persistence of myocardial sinusoids represents a congenital anomaly of embryogenic channels within the myocardium which is thought to result from incomplete capillarization ${ }^{[1]}$. It is almost always associated with pulmonary atresia with intact ventricular septum or congenital aortic or pulmonary valve stenosis ${ }^{[2,3]}$.

\section{Case report}

A boy with critical pulmonary valve stenosis and persisting right ventricular sinusoids underwent commissurotomy of the pulmonary valve at the age of 12 months. A postoperative follow-up study by cardiac catheterization was performed at the age of 17 years. Haemodynamic data are given in Table 1. Right ventricular angiocardiography showed apical right ventricular myocardial sinusoids and contractility was preserved best within the widened outflow tract but was generally impaired. There was mild tricuspid regurgitation.

The patient was restudied recently by Dopplerechocardiography at the age of 18 years. He was completely asymptomatic and clinical examination

Submitted for publication on 12 January 1989, and in revised form 12 April 1989.

Address for correspondence: R. Jenni, M.D., M.S.E.E., Medical Policlınıc, Division of Cardiology, University Hospital of Zürich, Rämistr. 100,8091 Zürich, Switzerland.
Table 1 Pressures $(\mathrm{mmHg}$ )

$\begin{array}{ll}\text { Right atrium } & a=18 ; \mathrm{v}=13 ; \text { mean }=10 \\ \text { RV inflow tract } & 20 / 8 \\ \text { RV outflow tract } & 21 / 10 \\ \text { PA trunk } & 20 / 9 ; \text { mean }=11\end{array}$

Cardiac index

$2 \cdot 81 \mathrm{~min}^{-1} \mathrm{~m}^{-2}$

$\mathbf{R V}=$ right ventricle; $\mathbf{P A}=$ pulmonary artery

revealed a $2 / 6$ systolic ejection murmur best heard over the pulmonary valve. Working capacity was normal. The chest $\mathrm{X}$-ray showed a slight enlargement of the heart with a cardiothoracic ratio of $0 \cdot 54$. Sinus rhythm and signs of right atrial and right ventricular hypertrophy were present in the ECG. Doppler echocardiographic recordings were performed using a Hewlett-Packard 77020AC machine including continuous-wave (CW) Doppler. Intramyocardial spaces representing persisting sinusoids at the right ventricular apex were visualized in the apical four-chamber view (Fig. 1). Continuouswave Doppler spectra were obtained by superimposing the $\mathrm{CW}$ beam on the 2-D image from an apical four-chamber view with the beam directed through the apical sinusoids (Fig. 2) and from a parasternal short axis view with the beam directed to the pulmonary trunk (Fig. 3). A systolic velocity jet corresponding to a pressure gradient of 


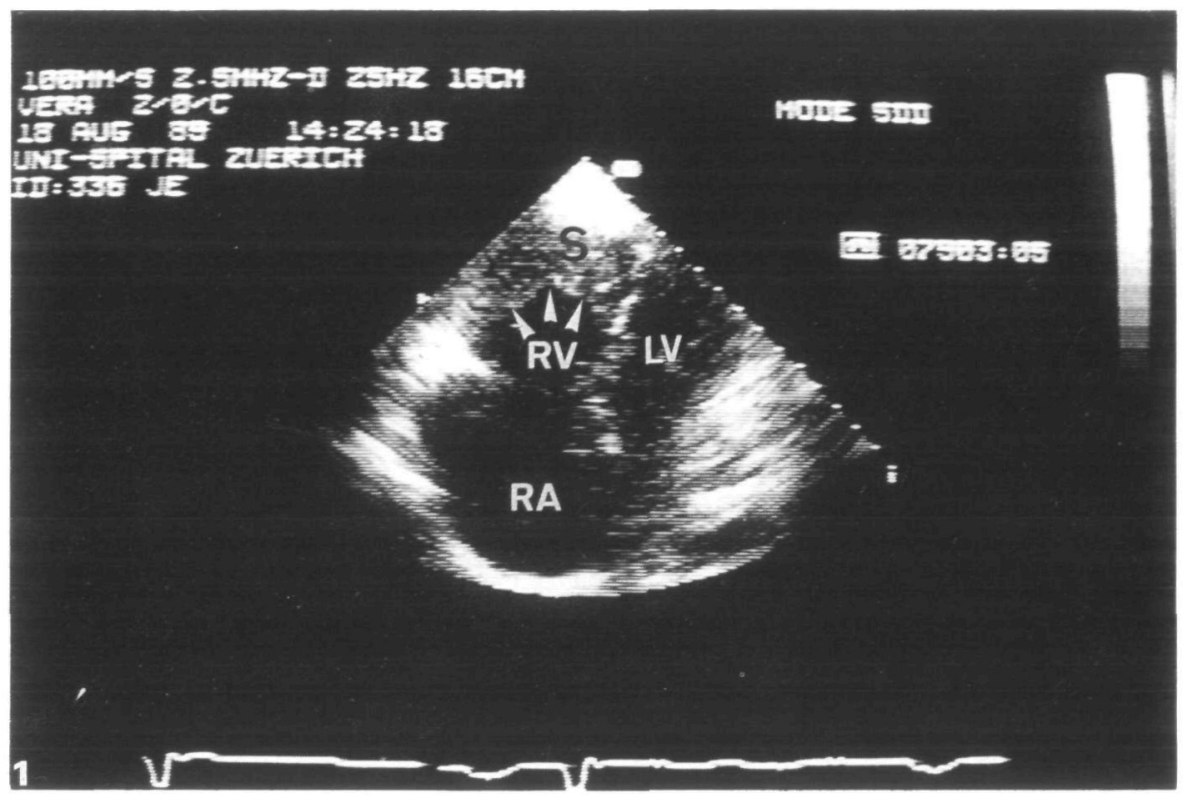

Figure I Apical four-chamber view. Intramyocardial sinusoids (S) are located at the apex (arrows) of the right ventricle ( $R V$ ). The right atrium (RA) is considerably enlarged. $L V=$ left ventricle. Calibration dots are indicated on the right border of the fan, separated by $1 \mathrm{~cm}$.

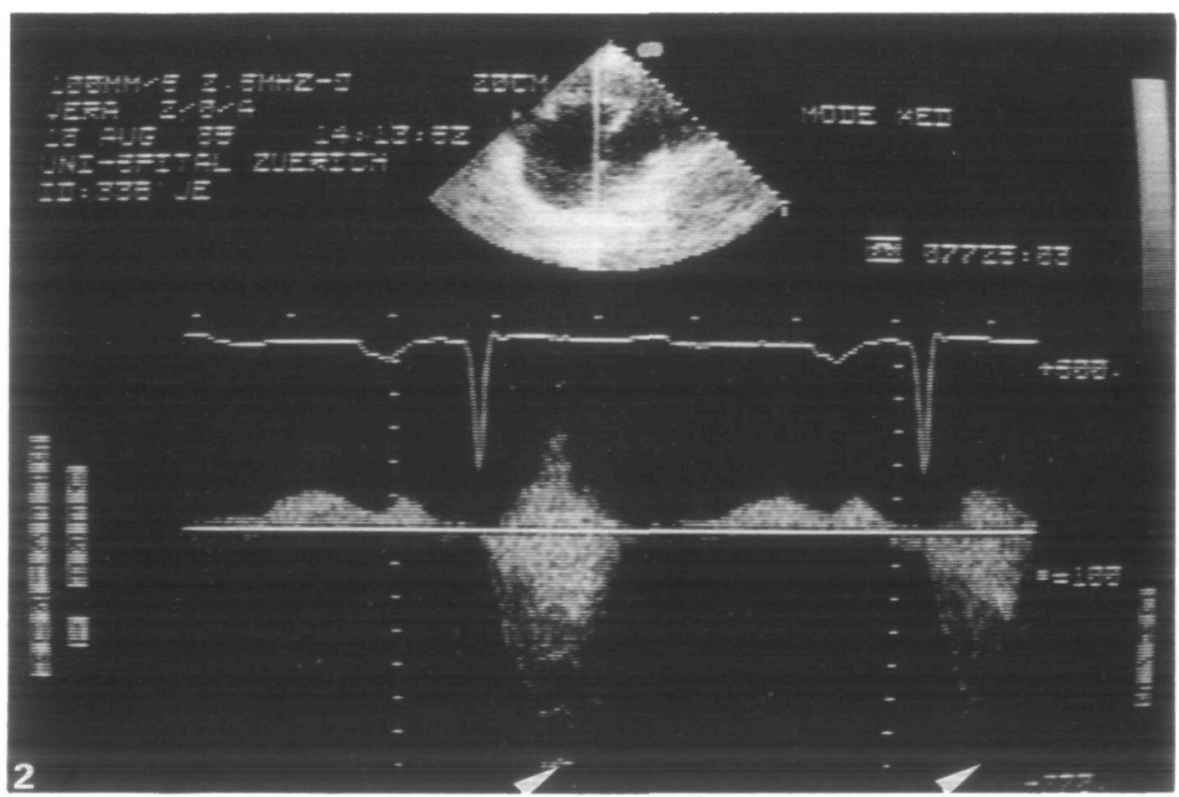

Figure 2 On top apical four-chamber view is shown. The direction of the CW beam (white line) interrogates the apical sinusoids. At the bottom the corresponding $\mathrm{CW}$ spectrum is displayed together with the ECG. Systolic peak velocity is about $6.5 \mathrm{~m}$ corresponding to a peak pressure gradient of $169 \mathrm{mmHg}$. Velocity calibration marks in the vertical axis correspond to $1 \mathrm{~m} \mathrm{~s}^{-1}$. 


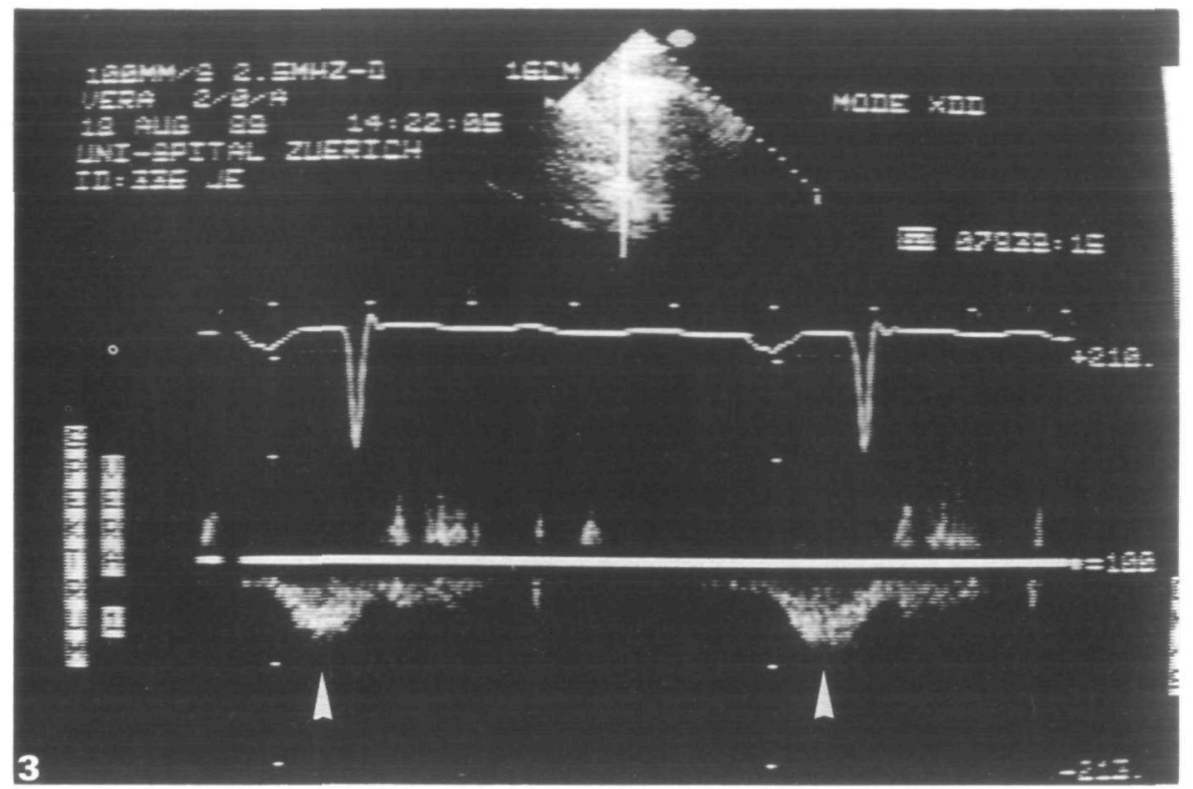

Figure 3 The CW spectrum from a parasternal short-axis view with the $\mathrm{CW}$ beam directed to the pulmonary artery is shown. Note (arrows) that forward flow within the pulmonary artery occurs mainly following atral contraction. Velocity calibratson marks in the vertical axis correspond to $1 \mathrm{~m} \mathrm{~s}^{-1}$

$169 \mathrm{mmHg}$ was measured within the sinusoids. There was no systolic pressure gradient between the right ventricular outflow tract and the pulmonary trunk. Moreover, pulmonary artery flow could be recorded mainly consequent to right atrial contraction, but was reduced during right ventricular systole (Fig. 3).

\section{Discussion}

To our knowledge, Doppler-echocardiographic features of patients with persisting myocardial sinusoids have not been reported so far in literature. In the present case, evidence for high systolic pressure gradients resulting from a 'space obliteration' effect within the persisting myocardial sinusoids was demonstrated using CW Doppler. The existence of right ventricular systolic velocity jets could be argued to be due to either tricuspid regurgitation alone or tricuspid regurgitation caused by increased impedance to right ventricular ejection in pulmonary valve stenosis, right ventricular outflow tract obstruction or pulmonary hypertension. CW Doppler recordings from within the pulmonary trunk as well as the cardiac catheterization data obtained the year before precluded these possibilities (Fig. 3). Moreover, systolic high velocity jets recorded within the sinusoids were clearly not coincident with tricuspid valve opening and closure and, hence, could not have originated from tricuspid regurgitation.

Pulmonary blood flow was shown to occur mainly following atrial contraction and was markedly reduced during right ventricular systole. This reflects impairment of systolic and diastolic right ventricular function associated with the persisting myocardial sinusoids. It is concluded that velocity jets during right ventricular systole can occur in persisting myocardial sinusoids as a consequence of 'space obliteration' and may easily be detected non-invasively using $\mathrm{CW}$ Doppler. These jets should not be confused with jets resulting from tricuspid regurgitation.

\section{References}

[1] Jenni R, Goebel N, Tartini R, Schneider J, Arbenz U, Oelz O. Persisting myocardial sinusoids of both ventricles as an isolated anomaly: echocardiographic, angiographic, and pathologic anatomical findings. Cardiovasc Intervent Radiol 1986; 9: 127-31. 
[2] Davignon AL, DuShane JW, Kinkald OW, Swan HJC. Pulmonary atresia with intact ventricular septum. Report of two cases studied by selective angiography and nght heart catheterization Am Heart J 1961; 62: 690-7.
[3] Ellot LP, Adams P, Edwards JE. Pulmonary atresıa with intact ventricular septum. Br Heart J 1963; 25.489-501. 